University of Nebraska - Lincoln

DigitalCommons@University of Nebraska - Lincoln

$5-1995$

\title{
A candidate genetic risk factor for vascular disease: A common mutation in methylenetetrahydrofolate reductase
}

P. Frosst

McGill University

H. J. Blom

University Hospital Nijmegen, Netherlands

R. Milos

McGill University

P. Goyette

McGill University

Christal A. Sheppard

University of Nebraska-Lincoln, christalsheppard@unl.edu

See next page for additional authors

Follow this and additional works at: https://digitalcommons.unl.edu/lawfacpub

Part of the Legal Studies Commons

Frosst, P.; Blom, H. J.; Milos, R.; Goyette, P.; Sheppard, Christal A.; Matthews, R. G.; Boers, G. J.H.; den Heijer, M.; Kluijtmans, L. A.J.; van den Heuvel, L. P.; and Rozen, Rima, "A candidate genetic risk factor for vascular disease: A common mutation in methylenetetrahydrofolate reductase" (1995). College of Law, Faculty Publications. 124.

https://digitalcommons.unl.edu/lawfacpub/124

This Article is brought to you for free and open access by the Law, College of at DigitalCommons@University of Nebraska - Lincoln. It has been accepted for inclusion in College of Law, Faculty Publications by an authorized administrator of DigitalCommons@University of Nebraska - Lincoln. 


\section{Authors}

P. Frosst, H. J. Blom, R. Milos, P. Goyette, Christal A. Sheppard, R. G. Matthews, G. J.H. Boers, M. den Heijer, L. A.J. Kluijtmans, L. P. van den Heuvel, and Rima Rozen 


\title{
A candidate genetic risk factor for vascular disease: A common mutation in methylenetetrahydrofolate reductase
}

\author{
P. Frosst,${ }^{1}$ H.J. Blom, ${ }^{2}$ R. Milos,${ }^{1}$ P. Goyette,${ }^{1}$ C. A. Sheppard,${ }^{3}$ R. G. Matthews,${ }^{3}$ G.J.H. Boers, ${ }^{4}$ \\ M. den Heijer, ${ }^{2}$ L.A.J. Kluijtmans, ${ }^{2}$ L. P. van den Heuvel, ${ }^{2}$ and R. Rozen ${ }^{1}$ \\ 1. Departments of Human Genetics, Pediatrics and Biology, McGill University, Montreal Children's Hospital, Montreal, Canada H3H 1P3 \\ 2. Department of Pediatrics, University Hospital Nijmegen, 6500 HB Nijmegen, The Netherlands \\ 3. Biophysics Research Division and Department of Biological Chemistry, University of Michigan, Ann Arbor, Michigan, 48109, USA \\ 4. Department of Medicine, University Hospital Nijmegen, 6500 HB Nijmegen, The Netherlands \\ 5. Department of Hematology, Municipal Hospital Leyenburg, $2545 \mathrm{CH}$ The Hague, The Netherlands
}

Corresponding author - R. Rozen

\begin{abstract}
Hyperhomocysteinaemia has been identified as a risk factor for cerebrovascular, peripheral vascular, and coronary heart disease..$^{1-4}$ Elevated levels of plasma homocysteine can result from genetic or nutrient-related disturbances in the trans-sulphuration or re-methylation pathways for homocysteine metabolism. ${ }^{1,5-7}$ 5,10-Methylenetetrahydrofolate reductase (MTHFR) catalyzes the reduction of 5,10-methylenetetrahydrofolate to 5-methyltetrahydrofolate, the predominant circulatory form of folate and carbon donor for the re-methylation of homocysteine to methionine. Reduced MTHFR activity with a thermolabile enzyme has been reported in patients with coronary and peripheral artery diseases. ${ }^{6}$ We have identified a common mutation in MTHFR which alters a highly-conserved amino acid; the substitution occurs at a frequency of approximately $38 \%$ of unselected chromosomes. The mutation in the heterozygous or homozygous state correlates with reduced enzyme activity and increased thermolability in lymphocyte extracts; in vitro expression of a mutagenized cDNA containing the mutation confirms its effect on thermolability of MTHFR. Finally, individuals homozygous for the mutation have significantly elevated plasma homocysteine levels. This mutation in MTHFR may represent an important genetic risk factor in vascular disease.
\end{abstract}

Severe MTHFR deficiency, the most common inborn error of folate metabolism, results in hyperhomocysteinaemia, homocystinuria, and hypomethioninaemia. Patients with severe MTHFR deficiency (0-20\% residual activity in cultured fibroblasts) present in infancy or adolescence with developmental delay, motor and gait dysfunction, seizures, psychiatric disturbances, and other neurological abnormalities; they are also at risk for vascular complications. ${ }^{8}$ Individuals with $50 \%$ residual activity, due to a thermolabile form of the reductase, were first reported in approximately 17\% of 212 North American patients with coronary artery disease. ${ }^{5}$ A recent study of the Netherlands population identified the thermolabile variant in different forms of premature vascular disease, ${ }^{6}$ and estimated its incidence to be $7 \%$ of vascular patients. The presence of a thermolabile MTHFR is predictive of coronary artery stenosis, independent of other risk factors, such as age, smoking, hypercholesterolaemia, and hypertension. ${ }^{9}$

Our recent isolation of a cDNA for human MTHFR ${ }^{10}$ has enabled us to identify nine mutations in this gene, in the severely-deficient group of patients, by SSCP analysis and direct sequencing of PCR fragments. ${ }^{10,11}$ Using the same procedures, we identified a $\mathrm{C}$ to $\mathrm{T}$ substitution at nucleotide (nt) 677 , which converts an alanine to a valine residue (Figure 1a). This alteration creates a HinfI site (Figure 1b), which was used to screen 114 unselected French Canadian chromosomes; the allele frequency of the substitution was 0.38 . The frequency of the three genotypes were as follows: $-/-, 37 \% ;+/-, 51 \%$; and $+/+, 12 \%$ ( + indicates the presence of the HinfI site and a valine residue). As these individuals were not examined clinically or biochemically, they cannot be considered as a control group.
We next performed genotypic analysis and measured enzyme activity and thermolability in a total of 40 lymphocyte pellets from patients with premature vascular disease and controls (Table I). We selected 13 vascular patients from our previous study, among whom five were considered to have thermolabile MTHFR. ${ }^{6}$ From a large reference group of 89 controls, we studied all seven individuals who had thermolabile MTHFR, and selected at random an additional 20 controls with normal MTHFR from the same reference group. The mean MTHFR activity for individuals homozygous for the Ala to Val substitution (+/+) was approximately $30 \%$ of the mean activity for (-/-) individuals. Heterozygotes had a mean MTHFR activity of $65 \%$ compared to $(-/-)$ individuals, intermediate between values for $(-/-)$ and $(+/+)$ individuals. The ranges of activities showed some overlap for the heterozygous and (-/-) genotypes, but homozygous $(+/+)$ individuals showed virtually no overlap with the other two groups. A one-way analysis of variance yielded a $P$ value <.0001;

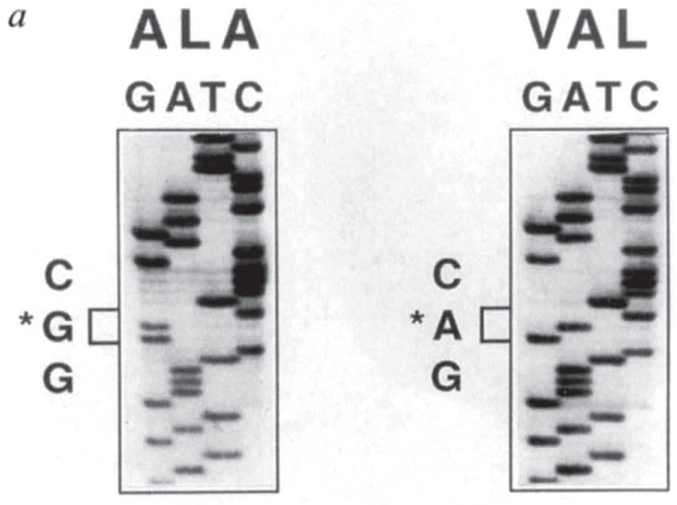

b

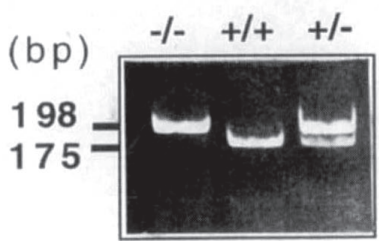

Figure 1. Sequence change and restriction enzyme analysis for the alanine to valine substitution. a) Sequence of two individuals, a homozygote for the alanine residue and a homozygote for the valine residue. The antisense strands are depicted. The primers for analysis of the $A \rightarrow V$ change are: 5'-TGAAGGAGAA GGTGTCTGCG GGA-3' (exonic) and 5'-AGGACGGTGC GGTGAGAGTG-3' (intronic); these primers generate a fragment of $198 \mathrm{bp}$. b) The substitution creates a Hinfl recognition sequence which digests the $198 \mathrm{bp}$ fragment into 175 and $23 \mathrm{bp}$ fragments; the latter fragment has been run off the gel. All three possible genotypes are shown. 
Table 1. Correlation between MTHFR genotype and enzyme activity, thermolability, and plasma homocysteine level

\begin{tabular}{|c|c|c|c|}
\hline & \multicolumn{3}{|c|}{ Genotype } \\
\hline & $\begin{array}{l}-1- \\
n=19\end{array}$ & $\begin{array}{l}+/- \\
n=9\end{array}$ & $\begin{array}{c}+/+ \\
n=12\end{array}$ \\
\hline $\begin{array}{l}\text { Specific activitya,b } \\
\left(\mathrm{nmol} \mathrm{CH} \mathrm{H}_{2} \mathrm{O} / \mathrm{mg} \text { protein/hr) }\right.\end{array}$ & $\begin{array}{c}22.9 \pm 1.7 \\
(11.8-33.8)\end{array}$ & $\begin{array}{c}15.0 \pm 0.8 \\
(10.2-18.8)\end{array}$ & $\begin{array}{c}6.9 \pm 0.6 \\
(2.6-10.2)\end{array}$ \\
\hline $\begin{array}{l}\text { Residual activity } \\
\text { after heatings }{ }^{a, b}(\%)\end{array}$ & $\begin{array}{r}66.8 \pm 1.5 \\
(55-76)\end{array}$ & $\begin{array}{c}56.2 \pm 2.8 \\
(41-67)\end{array}$ & $\begin{array}{c}21.8 \pm 2.8 \\
(10-35)\end{array}$ \\
\hline $\begin{array}{l}\text { Plasma homocysteine }{ }^{a, c} \\
(\mu \mathrm{M})(\text { after fasting) }\end{array}$ & $\begin{array}{c}12.6 \pm 1.1 \\
(7-21)\end{array}$ & $\begin{array}{r}13.8 \pm 1.0 \\
(9.6-20)\end{array}$ & $\begin{array}{l}22.4 \pm 2.9 \\
(9.6-42)\end{array}$ \\
\hline $\begin{array}{l}\text { Plasma homocysteine } e^{a, c} \\
(\mu \mathrm{M})(\text { post-methionine load) }\end{array}$ & $\begin{array}{l}41.3 \pm 5.0^{d} \\
(20.9-110)\end{array}$ & $\begin{array}{c}41 \pm 2.8 \\
(29.1-54)\end{array}$ & $\begin{array}{l}72.6 \pm 11.7^{\mathrm{e}} \\
(24.4-159)\end{array}$ \\
\hline
\end{tabular}

Enzyme activity and plasma homocysteine were determined as previously reported. ${ }^{6}$ Each value represents mean \pm standard error. The range is given in parentheses below the mean. a. one-way ANOVA $P<$ .01. b. paired $t$ test for all combinations $P<.01$. c. paired $t$ test $P<.05$ for + /+ group versus +/- group or -/- group; $P>.05$ for + /- versus $-/-$ group. d. $n=18$. e. $n=11$.

a pairwise Bonferroni $t$ test showed that all three genotypes were significantly different with $P<0.01$ for the three possible combinations.

The three genotypes were all significantly different $(P<.01)$ with respect to enzyme thermolability. The mean residual activity after heat inactivation $\left(5 \mathrm{~min}\right.$ at $\left.46^{\circ} \mathrm{C}\right)$ was $67 \%(-/-)$, $56 \%(+/-)$ and $22 \%(+/+)$. While the degree of thermolability overlaps somewhat for (-/-) individuals and heterozygotes, individuals with two mutant alleles had a distinctly lower range. Every individual with the $(+/+)$ genotype had residual activity $<35 \%$ after heating, and specific activity $<50 \%$ of that of the $(-/-)$ genotype.

Fasting homocysteine levels in $(+/+)$ individuals were almost twice the value for $(+/-)$ and $(-/-)$ individuals. The differences among genotypes for plasma homocysteine were maintained when homocysteine was measured following six hours of methionine loading. A one-way ANOva yielded a $P<$ .01 for the fasting and post-methionine homocysteine levels. A pairwise Bonferroni $t$ test showed that homozygous mutant individuals had significantly elevated homocysteine levels $(P$ $<.05)$,compared to either (+/-) or (-/-) individuals.

We have used the original MTHFR CDNA $(1.3 \mathrm{~kb})$ to isolate a $2.2 \mathrm{~kb}$ cDNA, which contained an additional $900 \mathrm{bp}$ at the $3^{\prime}$ end; the latter contained a termination codon, $100 \mathrm{bp}$ of $3^{\prime}$ UTR and a poly A tail (GenBank\# UO9806). The open reading frame of $1980 \mathrm{bp}$ predicts a protein of $74.6 \mathrm{kDa}$. The purified porcine liver enzyme has been shown to have subunits of $77 \mathrm{kDa} .{ }^{12}$ Western analysis (Figure 2a) of several human tissues and of porcine liver reveals a polypeptide of $77 \mathrm{kDa}$, as well as an additional polypeptide of approximately $70 \mathrm{kDa}$ in human fetal liver and in porcine liver, suggesting the presence of isozymes.

The wild-type cDNA and a mutagenized cDNA, containing the Ala to Val substitution, were expressed in E. coli to yield a protein of approximately $70 \mathrm{kDa}$ (Figure 2a), which co-migrates with the smaller polypeptide mentioned above. Treatment of extracts at $46^{\circ} \mathrm{C}$ for five minutes revealed that the enzyme containing the substitution was significantly more thermolabile than the wild -type enzyme $(P<.001$; Figure $2 b)$. The expression experiments were not designed to measure differences in specific activity before heating, since variation in efficiencies of expression could contribute to difficulties in interpretation. Curiously though, the specific activity for the mutant construct was higher in both experiments. It is possible that the mutant protein has increased stability in E. coli, or that inclusion bodies in our extracts contributed to differences in recovery of properly-assembled enzyme.

The alanine residue is conserved in porcine MTHFR and in the corresponding bacterial metF genes. ${ }^{10}$ We have also observed a region of homology in the human dihydrofolate reductase (DHFR) gene, ${ }^{11}$ although the alanine residue itself is not conserved; this region of amino acids 130-149 of DHFR contains Thr136, which has been implicated in folate binding of human DHFR. ${ }^{13}$ This region in MTHFR might also be involved in folate binding, and the enzyme may be stabilized in the presence of folate. This hypothesis is compatible with the well-documented influence of folate on homocysteine levels ${ }^{7,14}$ and with the reported correction of mild hyperhomocysteinaemia by folic acid in individuals with premature vascular disease $^{14}$ and thermolabile MTHFR. ${ }^{15}$
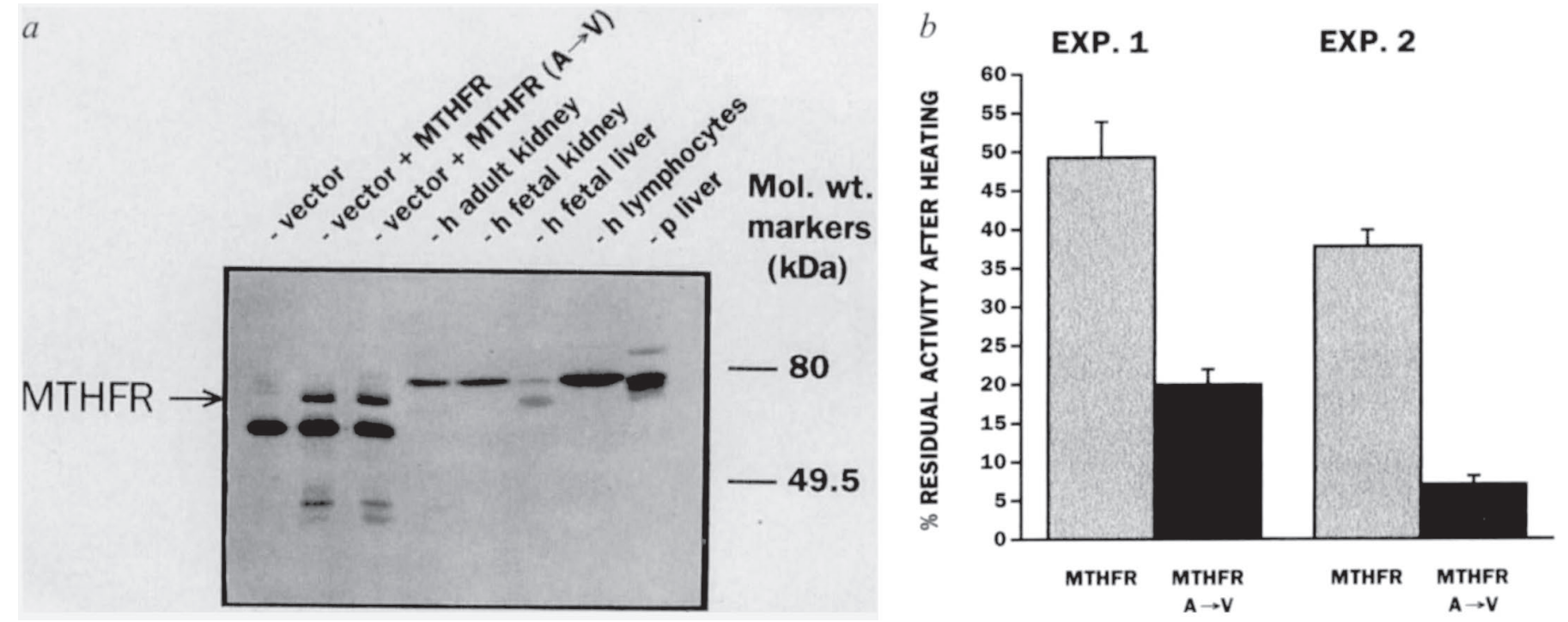

Figure 2. Expression analysis of MTHFR in E. coli. a) Western blot of bacterial extracts and tissues. Two $\mu$ g of bacterial extract protein was used for lanes 1-3. The tissues (lanes 4-6) were prepared by homogenization in $0.25 \mathrm{M}$ sucrose with aprotinin and leupeptin, followed by sonication on ice. The extracts were spun for $15 \mathrm{~min}$ in a microcentrifuge at $14,000 \mathrm{~g}$ and $100 \mu \mathrm{g}$ of supernatant protein was used for western analysis. $\mathrm{h}$, human; $p$, porcine. b) Thermolability assay of bacterial extracts. Two separate experiments (with 3-4 replicates construct experiment) were performed to measure thermostable activity of the wild-type and mutagenized MTHFR cDNAs. The values shown represent mean \pm standard error for each experiment, as \% of residual activity after heating. The means of the specific activities before heating (expressed as nmol formaldehyde/hr/ mg protein) were as follows: 3.8 and 5.3 (Exp. 1) and 6.2 and 7.5 (Exp. 2) for MTHFR and MTHFR A $\rightarrow$ V, respectively. 
Our data have identified a common genetic change in MTHFR which results in thermolability; our experiments do not directly address the relationship between this change and vascular disease. Nonetheless, this mutation represents a diagnostic test for evaluation of MTHFR thermolability in hyperhomocysteinaemia. Large case-control studies are required to evaluate the frequency of this genetic change in various forms of occlusive arterial disease and to examine the interaction between this genetic marker and dietary factors, such as folate intake. Well-defined populations need to be examined, as the limited data set thus far suggests that population-specific allele frequencies may exist. More importantly, however, the identification of a candidate genetic risk factor for vascular disease, which may be influenced by nutrient intake, represents a critical step in the design of appropriate therapies for the homocysteinaemic form of arteriosclerosis.

\section{Methodology}

Mutation identification. Primers were designed from the cDNA sequence to generate 250-300 bp fragments which overlapped 50-75 bp at each end. When PCR amplification of human genomic DNA yielded larger fragments than expected for the coding region alone, these fragments were presumed to contain introns and were sequenced directly (Cycle Sequencing kit, GIBCO). Intronic primer sequences were obtained with this strategy. PCR products were analyzed by a non-radioactive SSCP protocol as described. ${ }^{10}$ Fragments showing a shift on SSCP gels were subcloned into Bluescript and sequenced (Sequenase kit, USB). To confirm the sequence changes, a new PCR was performed with genomic DNA; the PCR product was digested with HinfI and analyzed by polycrylamide gel electrophoresis.

Clinical material. To determine the frequency of the $\mathrm{A} \rightarrow \mathrm{V}$ mutation, DNA from 57 individuals from Quebec was analyzed by PCR and restriction digestion. The individuals, all French Canadian, were not examined clinically or biochemically. The 40 individuals analyzed in Table 1 have been described. ${ }^{6}$ Of the 13 cardiovascular patients, eight had cerebrovascular arteriosclerosis, and five had peripheral arteriosclerosis. Five had thermolabile MTHFR, while eight had thermostable MTHFR (>33\% residual activity after heating). Controls and patients were all Dutch-Caucasian, between 20-60 years of age. None of these individuals used vitamins that could alter homocysteine levels. Enzyme assays and homocysteine determinations have also been reported. ${ }^{6}$

Constructs for expression analysis. A human colon carcinoma cDNA library (gift of Nicole Beauchemin, McGill University) was screened by plaque hybridization with the original $1.3 \mathrm{~kb} \mathrm{cDNA}^{10}$ to obtain additional coding sequences. A cDNA of $2.2 \mathrm{~kb}$ was isolated, which contained 900 additional bp at the $3^{\prime}$ end (Genbank accession number UO9806). Sequencing was performed on both strands for the entire cDNA. Additional 5' sequences ( $800 \mathrm{bp}$ ) were obtained from a human kidney cDNA library (Clontech), but these sequences did not contain additional coding sequences and were therefore used for the PCR-based mutagenesis only (see below) and not for the expression analysis. The two cDNAs $(2.2 \mathrm{~kb}$ and $800 \mathrm{bp}$ ) were ligated using the EcoRI site at nt 199 and inserted into Bluescript (Stratagene). The $2.2 \mathrm{~kb}$ cDNA was subcloned into the expression vector pTrc99A (Pharmacia) using the NcoI site at nt 11 and the XbaI site in the polylinker region of both vectors. Sequencing was performed across the cloning sites to verify the wild-type construct.

PCR-based mutagenesis, using the cDNA-containing Bluescript vector as template, was used to create the A to V mutation identified. ${ }^{16}$ Vent polymerase (NEB) was used to reduce PCR errors. The following primers were used: primer 1, bp -200 to -178, sense; primer 2, bp 667 to 687 , antisense, containing a mismatch, $\mathrm{A}$, at nt 677 ; primer 3,667 to 687, sense, containing a mismatch, T, at nt 677; primer 4, bp 1092 to 1114 , antisense. PCR was performed using primers 1 and 2 to generate a product of $887 \mathrm{bp}$, and using primers 3 and 4 to generate a product of $447 \mathrm{bp}$. The two PCR fragments were isolated from a 1.2\% agarose gel by Geneclean (BIO 101). A final PCR reaction, using primers 1 and 4 and the first two PCR fragments as template, was performed to generate a $1.3 \mathrm{~kb}$ band containing the mutation. The $1.3 \mathrm{~kb}$ fragment was digested with $\mathrm{NcoI}$ and $\mathrm{MscI}$, and inserted into the wild-type cDNAcontaining expression vector by replacing the sequences between the NcoI site at bp 11 and the MscI site at bp 943 . The entire replacement fragment and the cloning sites were sequenced to verify that no additional changes were introduced by PCR.
Expression analysis. Overnight cultures of JM 105 containing vector, wild-type, or mutagenized MTHFR cDNA were grown at $37^{\circ} \mathrm{C}$ in 2 $\times$ YT media with $.05 \mathrm{mg} \mathrm{ml}^{-1}$ ampicillin. Fresh $10 \mathrm{ml}$ cultures of each were inoculated with approximately $50 \mu \mathrm{l}$ of overnight cultures and grown at $37^{\circ} \mathrm{C}$ to an O.D. of 1 at $420 \mathrm{nM}$. Cultures were then induced for $2 \mathrm{~h}$ with $1 \mathrm{mM}$ IPTG and pelleted. The cells were resuspended in TE buffer with $2 \mu \mathrm{g} \mathrm{ml}^{-1}$ aprotinin and leupeptin $(3.5 \times$ wet weight of cells). Cell suspensions were sonicated on ice for $3 \times 15 \mathrm{~s}$ and centrifuged for $30 \mathrm{~min}$ at $4{ }^{\circ} \mathrm{C}$ to pellet cell debris and unlysed cells. The supernatant was removed and assayed for protein concentration with the Bio-Rad protein assay. Western analysis was performed using the Amersham ECL kit with antiserum generated against purified porcine liver MTHFR. ${ }^{12}$ Enzymatic assays were performed by established procedures. ${ }^{17}$ Thermolability was assessed by pre-treating the extracts at $46^{\circ} \mathrm{C}$ for $5 \mathrm{~min}$ before determining activity. Specific activities (nmol formaldehyde $/ \mathrm{h} / \mathrm{mg}$ protein) were calculated for the $2 \mathrm{cDNA}$-containing constructs after subtraction of the values obtained with vector alone (to subtract background E. coli MTHFR activity).

Acknowledgments - We thank E. Stevens, H. van Lith-Zanders, C Mandel, and N. Beauchemin for their contribution to this work. This work was supported by the Medical Research Council of Canada (R.R.), the Canadian Heart and Stroke Foundation (R.R.), in part by the Netherlands Heart Foundation (H.B.), and by NIH Grant R37 GM24908 (CA.S. and R.G.M.). R.R. is a Principal Investigator of the MRC Group in Medical Genetics.

\section{References}

1. Boers. G.H.J. et al. Heterozygosity for homocystinuria in premature peripheral and cerebral occlusive arterial disease. New Engl. J. Med. 313, 700-715 (1985).

2. Genest, J.J. Jr. et al. Plasma homocysteine levels In men with premature coronary artery disease. J. Am. Coll. Cardiol. 18, 1114-1119 (1990).

3. Clarke, R. et al. Hyperhomocysteinemia: An independent risk factor for vascular disease. New Engl. J. Med. 324, 1149-1155 (1991)

4. Stampfer, M. J. et al. A prospective study of plasma homocysteine and risk of myocardial infarction in US physicians. J. Am. Med. Assoc. 288, 877-881 (1992).

5. Kang, S.-S. et al. Thermolabile methylenetetrahydrofolate reductase: An inherited risk factor for coronary artery disease. Am. J. Hum. Genet. 48, 536-545 (1991).

6. Engbersen, A.M.T. et al. Thermolabile 5,10-methylenetetrahydrofolate reductase as a cause of mild hyperhomocysteinaemia. Am. J. Hum. Genet. 56, 142-150 (1995).

7. Selhub, J., Jacques, P. F., Wilson, P.W.F., Rush, D., \& Rosenberg, I. H. Vitamin status and intake as primary determinants of homocysteinemia in an elderly population, J. Am. Med. Assoc. 270, 2693-2698 (1993).

8. Rosenblatt, D. S. in The Metabolic Basis of Inherited Disease (ed. Scriver, C. R., Beaudet, A. L, Sly, W. S., \& Valle, D.) 2049-2064 (McGraw-Hill, New York, 1989).

9. Kang, S.-S., Passen, E. L., Ruggie, N., Wong, P.W.K., \& Sora, H. Thermolabile defect of methylenetetrahydrofolate reductase in coronary artery disease. Circulation 88,1463-1469 (1993).

10. Goyette, P. et al. Human methylenetetrahydrofolate reductase: Isolation of CDNA, mapping and mutation identification. Nature Genet. 7 , 195-200 (1994).

11. Goyette, P., Frosst, P., Rosenblatt, D. S. ,\& Rozen, R. Seven novel mutations in the methylenetetrahydrofolate reductase gene and genotype/ phenotype correlations in severe methylenetetrahydrofolate reductase deficiency. Am. J. Hum. Genet. 56, 1052-1059 (1995).

12. Daubner, S. C. \& Matthews, R. G. Purification and properties of methylenetetrahydrofolate reductase from pig liver. J. Biol. Chem. 251. 140145 (1982).

13. Davies, J. F., et al. Crystal structures of recombinant human dihydrofolate reductase complexed with folate and 5-deazafolate, J. Biochem. 29, 9467-9479 (1990).

14. Franken, D. G., Boers, G.H.J., Blom, H. J, Trijbels, J.M.F., \& Kloppenborg, P.W.C. Treatment of mild hyperhomocysteinemiain vascular disease patients. Arterioscler. Thromb. 14, 465-470 (1994).

15. Kang, S.-S., Zhou, J., Wong, P.W.K., Kowalisyn, J., \& Strokosch, G. Intermediate homocysteinemla: A thermolabile variant of methylenetetrahydrofolate reductase. Am. J. Hum. Genet. 43, 414-421 (1988).

16. Horton, R. M., et al. Gene splicing by overlap extension. Math. Enzymol. 217, 270-279 (1993).

17. Rosenblatt, D. S. \& Erbe, R. W. Methylenetetrahydrofolate reductase in cultured human cells. I. Growth and metabolic studies. Pediatr. Res. 11, 1137-1141 (1977). 